\title{
Evaluation of Nutritional Status as a Prognostic Indicator for the Outcome in Liver Transplant Recipients
}

\author{
MOHAMED A.M. ALI, M.D.*; RANDA A. SHOUKRY, M.D.*; DALIA F. EMAM, M.D.*; \\ EMAN I. EL-DESOKI MAHMOUD, M.D.** and MOHAMED I.I. AKP EL-BAB, M.Sc.*
}

The Department of Anesthesiology, General Intensive Care Medicine \& Pain Management, Faculty of Medicine, Ain Shams University* and Fellow of General Intensive Care, National Hepatology \& Tropical Medicine Research Institute, Cairo**

\begin{abstract}
Background: Mal-nutrition is a common complication of the end-stage liver disease and associated with increased morbidity and mortality rates. Numerous studies have proved that pre-operative mal-nutrition is related to higher risk of surgical morbidities and mortalities in general surgical patients. Mal-nourished patients tend to have high rates of infectious complications, prolonged intensive care unit (ICU) stay, hospital stay and increased mortality.

Aim of Study: To determine the impact of nutritional status pre-liver transplant on recipients' course and the outcome post-transplant.

Patients and Methods: Pre-operative nutritional assessment with Subjective global assessment (SGA) was done retrospectively for 52 patients, categorized as well-nourished, mild, moderate and severe mal-nourished and followed for postoperative course.

Results: The causes of transplant were mainly decompensated chronic liver disease $(46.2 \%)$, hepato-cellular carcinoma $(32.7 \%)$ and auto-immune with HCC $(11.5 \%)$. As a result of all these complications, the ICU stay, hospital stay, 28 day mortality were less in well-nourished patients in comparison to the mal-nourished one.

Conclusion: The nutritional status pre-liver transplant is an important factor which can affect the outcome of the liver transplant patients. The mal-nourished patients showed a higher incidence of post-operative sepsis, a higher postoperative bilirubin levels, a more need for post-operative nutritional intervention, a higher incidence of need of reintubation for mechanical ventilation, a higher incidence of post-operative renal impairment and neurological complications. As a result of all these complications, the ICU stay, hospital stay, 28 day mortality were less in well-nourished patients in comparison to the mal-nourished one. So, preoperative assessment and optimizing the nutritional status is an essential step before proceeding for surgery.
\end{abstract}

Correspondence to: Dr. Mohamed I.I. Akp El-Bab, E-Mail: mohamedakpelbab@gmail.com
Key Words: Malnutrition-Mal-nourished-Well-nourished - Liver transplantation - SGA - HCC - Decompansated chronic liver disease - TPN - Demographic data-BMI-Post-operative - Nutritional intervention - Stay - Mortality - Liver functions - Sepsis-Renal.

\section{Introduction}

LIVER transplantation is a viable treatment option for end-stage liver disease and acute liver failure. The surgical procedure is very demanding and ranges from 4 to 18 hours depending on outcome. Numerous anastomoses and sutures, and many disconnections and reconnections of abdominal and hepatic tissue, must be made for the transplant to succeed, requiring an eligible recipient and a well-calibrated live or cadaveric donor match. By any standard, hepatic transplantation is a major surgical procedure [1]

Malnutrition is associated with increased morbidity and mortality rates in patients with chronic liver disease. Patients with cirrhosis who are malnourished have a higher rate of hepatic encephalopathy, infection, and variceal bleeding. They are also twice as likely to have refractory ascites. Numerous studies have found a correlation between poor nutritional status and a decreased survival rate [1]

Nutritional status has a prognostic implications in liver transplant candidates. Malnutrition before transplantation is associated with a higher rate of post-transplant complications, including infection and variceal bleeding. Patients who are severely malnourished require more blood products intraoperatively, stay on ventilatory support longer postoperatively, and have an increased length of 
hospital stay and a higher incidence of graft failure. Ultimately, patients with poor nutritional status before transplant surgery have a decreased survival rate after liver transplantation [2]

Checking all patients with chronic liver disease for nutritional abnormalities can detect those at risk of developing preventable complications. Starting nutritional therapy during all phases of liver transplant has the possibility to decrease the risk of such complications [3].

\section{Aim of the work:}

The purpose of this study was to determine the impact of nutritional status pre-liver transplant on recipients' course and the outcome post-transplant.

\section{Patients and Methods}

\section{Type of study: Retrospective Cohort Study.}

Study setting: Subjective global assessment (SGA) was done retrospectively for patients and followed for operative course.

Study period: Analysis of the patient files from 2013 to 2017.

Study population: All patients prepared for liver transplantation and had undergone liver transplantation at National Hepatology and Tropical Medicine Research Institute (NHTMRI).

Inclusion criteria: All patients included in the study were candidate, prepared for the liver transplantation. They underwent preoperative nutritional assessment with subjective global assessment (SGA) and categorized as well-nourished or mild, moderate and severe malnourished.

Exclusion criteria: Patients were excluded if they have received nutritional support prior to the transplant, or if patient exposed to more than one organ transplantation at the same time.

Sampling method: All patients enrolled in the study were recipients of liver transplantation who were nutritionally assessed pre- operatively with SGA and started ordinary oral feeding on day one post-transplantation and received the full caloric requirements on day three.

Sample size: Fifty two (52) patients.

Ethical considerations: Prior to collection of study data, written approval from administrator was achieved. The study was ethically approved. Also from the Ethical Committee of the Institute.
Study procedures: Demographic data (age, gender and co-morbidities) were recorded. The cause of liver transplant, pre-operative liver status with (Child-Pugh score), frequent hospitalization or ICU admission prior transplantation, preoperative kidney (creatinine clearance) and pre-transplant nutritional assessment with SGA were recorded.

Patients were followed and assessed posttransplantation regarding daily sequential organ failure assessment score (SOFA score), the time of extubation, re-need for mechanical ventilation (cause, invasive or non-invasive and duration), morbidities that were developed during ICU stay; sepsis (when, site, total leucocytic count, $\mathrm{C}$ reactive protein (CRP), band cells \%, procalcitonin, culture and sensitivity, renal impairment (creatinine clearance and need for dialysis), neurological complications, graft function delay (synthetic function, excretory function and liver enzymes) and need for nutritional intervention (time of initiation and enteral or parenteral), ICU stay (according to management protocol, patient transferred to ward at day five), hospital stay and 28 day mortality.

All data were collected and mean \pm SD was taken: According to NHTMRI early ICU management protocol: All patients started ordinary oral feeding on day one and received the full caloric requirements on day three; if patients not extubated on day one due to any respiratory problems, patient start Ryle feeding till extubated and then started oral feeding. If patient had any surgically problems, feeding postponed till patient become surgically stable and then oral feeding started. Total parenteral nutrition (TPN) started if patient was mal-nourished or have any surgical problem that required stoppage of enteral feeding. The time of extubation; 12 hours post-operative, sedation stopped and patient extubated if hemodynamically stable, conscious with respiratory and ventilator parameters are accepted. If there was any respiratory problem, extubation postponed till condition be stabilized. Pan culture and sensitivity including drains sent on day zero and day three. Twenty four hours urine collection sent to measure creatinine clearance on day zero. Daily complete blood count (CBC) with differential, CRP, KFTs and LFTs (T.bil, D.bil, AST, ALT, INR, Albumin) done. Procalcitonine sent every other day in normal conditions and daily if there is severe infection. Intensive Care Unit stay, usually 4 days and patient transferred to ward on day five. If patient developed any complications, patient transfer postponed till condition stabilized and patient be fit for transfer. 


\section{Statistical analysis:}

Recorded data were analyzed using the statistical package for social sciences, version 20.0 (SPSS Inc., Chicago, Illinois, USA). Quantitative data were expressed as mean \pm standard deviation (SD). Qualitative data were expressed as frequency and percentage.

The following tests were done:

A one-way analysis of variance (ANOVA) when comparing between more than two means. Post Hoc test: Least Significant Difference (LSD) was used for multiple comparisons between different variables. Chi-square $\left(\chi^{2}\right)$ test of significance was used in order to compare proportions between qualitative parameters. The confidence interval was set to $95 \%$ and the margin of error accepted was set to $5 \%$. So, the $p$-value was considered significant as the following: Probability ( $p$-value): $p$-value $\leq 0.05$ was considered significant (S). $p$ value $\leq 0.001$ was considered as highly significant (HS). $p$-value $>0.05$ was considered insignificant (NS).

\section{Results}

Table (1) shows the demographic data. The patients' age with mean \pm SD was $(47.77 \pm 9.77)$ years. Total number of male was $43(82.7 \%)$ and female was 9 (17.3\%). Body mass index was with mean \pm SD $(26.56 \pm 3.67) \mathrm{kg} / \mathrm{m}^{2}$. Patients who had DM represent (26.9\%) and those with HTN were $(7.7 \%)$.

Table (2) shows the correlation between subjective global assessment and demographic data where severe mal-nourished group had lowest weight and BMI and this correlation was statistically significant ( $p$-value 0.003 and $<0.001$ ) respectively.

Table (1): Demographic data.

\begin{tabular}{ll}
\hline Demographic data & Total $(\mathrm{n}=52)$ \\
\hline Age (years) (mean \pm SD) & $47.77 \pm 9.77$ \\
Gender $($ No. $=\%):$ & \\
$\quad$ Male & $43(82.7 \%)$ \\
$\quad$ Female & $9(17.3 \%)$ \\
Weight $(\mathrm{kg})($ mean \pm SD) & $78.75 \pm 11.29$ \\
$\quad$ Weight $(\mathrm{kg})$ & \\
BMI $\quad$ (mean $\pm \mathrm{SD})$ & $26.56 \pm 3.67$ \\
DM (No. $=\%):$ & \\
$\quad$ No & \\
$\quad$ Yes & $38(73.1 \%)$ \\
HTN (No. $=\%):$ & $14(26.9 \%)$ \\
$\quad$ No & \\
$\quad$ Yes & $48(92.3 \%)$ \\
*BMI = Body mass index. & $4(7.7 \%)$ \\
*DM = Diabetes mellitus. & \\
*HTN = Hypertension. &
\end{tabular}

Table (2): The correlation between subjective global assessment and demographic data.

\begin{tabular}{|c|c|c|c|c|c|c|}
\hline \multirow[b]{2}{*}{ Demographic data } & \multicolumn{4}{|c|}{ Subjective global assessment } & \multirow[b]{2}{*}{$\mathrm{F} / \mathrm{x}^{2} \#$} & \multirow[b]{2}{*}{$p$-value } \\
\hline & $\begin{array}{c}\text { Well } \\
(n=17)\end{array}$ & $\begin{array}{c}\text { Mild } \\
(n=12)\end{array}$ & $\begin{array}{l}\text { Moderate } \\
\quad(n=17)\end{array}$ & $\begin{array}{c}\text { Severe } \\
(n=6)\end{array}$ & & \\
\hline Age (years) & $47.53 \pm 10.71$ & $48.50 \pm 10.77$ & $47.00 \pm 7.69$ & $49.17 \pm 12.50$ & 0.096 & 0.962 \\
\hline $\begin{array}{l}\text { Gender: } \\
\text { Male } \\
\text { Female }\end{array}$ & $\begin{array}{l}11(64.7 \%) \\
6(35.3 \%)\end{array}$ & $\begin{array}{l}11(91.7 \%) \\
1(8.3 \%)\end{array}$ & $\begin{array}{l}16(94.1 \%) \\
1(5.9 \%)\end{array}$ & $\begin{array}{l}5(83.3 \%) \\
1(16.7 \%)\end{array}$ & $6.070 \#$ & 0.108 \\
\hline Weight (kg) & $79.71 \pm 9.22$ & $86.25 \pm 10.76 \mathbf{a}$ & $76.82 \pm 10.02 \mathbf{b}$ & $66.50 \pm 11.04$ abc & 5.455 & $0.003 *$ \\
\hline BMI $\frac{\text { Weight }(\mathrm{kg})}{[\text { Height }(\text { meter })]^{2}}$ & $28.34 \pm 3.38$ & $27.35 \pm 2.78$ & $25.97 \pm 3.36^{\mathbf{a b}}$ & $21.58 \pm 2.09 \mathbf{a b c}$ & 7.353 & $<0.001 * *$ \\
\hline $\begin{array}{l}\text { DM: } \\
\text { No } \\
\text { Yes }\end{array}$ & $\begin{array}{l}12(70.6 \%) \\
5(29.4 \%)\end{array}$ & $\begin{array}{l}9(75.0 \%) \\
3(25.0 \%)\end{array}$ & $\begin{array}{l}13(76.5 \%) \\
4(23.5 \%)\end{array}$ & $\begin{array}{l}4(66.7 \%) \\
2(33.3 \%)\end{array}$ & $0.301 \#$ & 0.960 \\
\hline $\begin{array}{l}H T N: \\
\text { No } \\
\text { Yes }\end{array}$ & $\begin{array}{l}15(88.2 \%) \\
2(11.8 \%)\end{array}$ & $\begin{array}{l}12(100.0 \%) \\
0(0.0 \%)\end{array}$ & $\begin{array}{l}16(94.1 \%) \\
1(5.9 \%)\end{array}$ & $\begin{array}{l}5(83.3 \%) \\
1(16.7 \%)\end{array}$ & $2.156 \#$ & 0.541 \\
\hline $\begin{array}{l}\text { F-One Way ANOVA. } \\
\# \mathrm{x}^{2}: \text { Chi-square test. } \\
p \text {-value }>0.05 \mathrm{NS} . \\
{ }^{*} p \text {-value }<0.05 \mathrm{~S} . \\
* * p \text {-value }<0.001 \mathrm{HS} .\end{array}$ & $\begin{array}{l}\text { Post HOC tes } \\
\text { a: Significa } \\
\text { b: Significa } \\
\text { c: Significa }\end{array}$ & $\begin{array}{l}\text { ifference with "w } \\
\text { lifference with "m } \\
\text { ifference with "m }\end{array}$ & $\begin{array}{l}\text { group. } \\
\text { group . } \\
\text { ate" group. }\end{array}$ & & & \\
\hline
\end{tabular}


This table shows the causes of liver transplantation and it was mainly due to decompensated CLD which represent $(46.2 \%)$ of enrolled patients, HCC represents (32.7\%), while Cryptogenic was (5.8\%); PSC and Wilson each represent (1.9\%).

This table shows the correlation between subjective global assessment and causes of liver transplant. Patients who were well nourished by SGA had the least cause of decompensated CLD in comparison with the other three groups with statistically significant $p$-value (0.004 and 0.005$)$ respectively.
Table (3): Causes of liver transplantation.

\begin{tabular}{ll}
\hline Causes & Total $(\mathrm{n}=52)$ \\
\hline Decompensated CLD & $24(46.2 \%)$ \\
HCC & $17(32.7 \%)$ \\
Autoimmune with HCC & $6(11.5 \%)$ \\
Cryptogenic & $3(5.8 \%)$ \\
PSC & $1(1.9 \%)$ \\
Wilson & $1(1.9 \%)$ \\
\hline
\end{tabular}

$* \mathrm{CLD}=$ Chronic liver disease.

$* \mathrm{HCC}=$ Hepatocellular carcinoma

$*$ PSC $=$ Primary sclerosing cholangitis.

Table (4): The correlation between subjective global assessment and causes of liver transplant.

\begin{tabular}{|c|c|c|c|c|c|c|}
\hline \multirow[b]{2}{*}{ Causes } & \multicolumn{4}{|c|}{ Subjective global assessment } & \multirow[b]{2}{*}{$x^{2}$} & \multirow[b]{2}{*}{$p$-value } \\
\hline & $\begin{array}{c}\text { Well } \\
(\mathrm{n}=17)\end{array}$ & $\begin{array}{l}\text { Mild } \\
(\mathrm{n}=12)\end{array}$ & $\begin{array}{c}\text { Moderate } \\
(\mathrm{n}=17)\end{array}$ & $\begin{array}{l}\text { Severe } \\
(\mathrm{n}=6)\end{array}$ & & \\
\hline Autoimmune, $\mathrm{HCC}$ & $2(11.8 \%)$ & $1(8.3 \%)$ & $2(11.8 \%)$ & $1(16.7 \%)$ & 0.277 & 0.963 \\
\hline Decompensated CLD & $1(5.9 \%)$ & $7(58.3 \%) \mathbf{a}$ & $13(76.5 \%) \mathbf{a}$ & $3(50.0 \%) \mathbf{a}$ & 18.133 & $0.004 *$ \\
\hline $\mathrm{HCC}$ & $12(70.6 \%)$ & $3(25.0 \%) \mathbf{a}$ & $1(5.9 \%) \mathbf{a b}$ & $1(16.7 \%) \mathbf{a}$ & 17.671 & $0.005^{*}$ \\
\hline Cryptogenic & $2(11.8 \%)$ & $1(8.3 \%)$ & $0(0.0 \%)$ & $0(0.0 \%)$ & 2.677 & 0.441 \\
\hline PSC & $0(0.0 \%)$ & $0(0.0 \%)$ & $0(0.0 \%)$ & $1(16.7 \%)$ abc & 7.817 & $0.049 *$ \\
\hline Wilson & $0(0.0 \%)$ & $0(0.0 \%)$ & $1(5.9 \%)$ & $0(0.0 \%)$ & 2.099 & 0.552 \\
\hline $\begin{array}{l}\mathrm{x}^{2}: \text { Chi-square test. } \\
{ }^{*} p \text {-value }<0.05 \mathrm{~S} .\end{array}$ & $\begin{array}{l}\text { Post HOC te } \\
\text { a: Signific } \\
\text { b: Signific } \\
\text { c: Signific }\end{array}$ & $\begin{array}{l}\text { erence with " } \\
\text { erence with "1 }\end{array}$ & $\begin{array}{l}\text { group. } \\
\text { group . } \\
\text { ate" group. }\end{array}$ & & & \\
\hline
\end{tabular}

This table shows the post-operative clinical course which reveals that Sequential Organ Failure assessment (SOFA) on admission with mean \pm SD (9.44 \pm 3.58$)$ and on discharge with mean \pm SD (3.94 \pm 3.11$)$. Time of extubation post-liver transplantation with mean \pm SD $(12.95 \pm 7.62)$ hours. Regarding re-need for mechanical ventilation (MV) was reported in 5 patients $(9.6 \%)$, patients who needed the invasive type of MV were three patients $(60 \%)$, while the non-invasive type was needed for only two patients (40\%).

Nutritional intervention was planned for ten patients $(19.2 \%)$. Sepsis developed in 9 patients $(17.3 \%)$, it was mainly on day zero and was due to chest infection. Renal Impairment happened in 18 patients (34.6\%); two of them needed renal replacement therapy. While neurological complications occurred in 9 patients (17.3\%), one of them due to ischemic stroke and others were due to drug related complications. Intensive Care Unit stay with mean \pm SD $(6.40 \pm 2.55)$ days, Hospital stay with mean \pm SD $(20.88 \pm 6.70)$ days and 28 day mortality was three patients $(5.8 \%)$.

This table shows the correlation between subjective global assessment and post-operative clinical course which shows that the majority of patients who needed nutritional intervention were in the severe and moderate mal-nourished groups with statistically significant $p$-value (0.010).

This table shows the different routes of nutritional intervention in which the majority of patients did not need nutritional intervention $(80.8 \%)$, while the parenteral route represents $(13.5 \%)$, enteral was $(3.8 \%)$ and $(1.9 \%)$ for both routes of nutrition.

This table shows correlation between subjective global assessment and the routes of nutritional intervention which shows that well and mild nourished groups were the least to need nutritional intervention in comparison to both moderate and severe groups and this was statistically significant ( $p$-value 0.012 ). The parenteral route was highest in the severe mal-nourished group (50\% of patients) and this was statistically significant too ( $p$-value 0.019 ).

This table shows the correlation between subjective global assessment and liver functions where bilirubin levels (total and direct) were higher in both moderate and severe mal-nourished groups and this had statistically significant $p$-value (0.007). 
Table (5): Post-operative clinical course.

\begin{tabular}{ll}
\hline Post-operative & Total $(\mathrm{n}=52)$ \\
\hline SOFA (admission) (mean \pm SD) & $9.44 \pm 3.58$ \\
SOFA (discharge) (mean \pm SD) & $3.94 \pm 3.11$ \\
Time of extubation (hrs.) (mean \pm SD) & $12.95 \pm 7.62$ \\
Re-need for mechanical ventilation & \\
(No .=\%): & \\
$\quad$ - No & $47(90.4 \%)$ \\
$\quad$ - Yes & $5(9.6 \%)$ \\
Cause of re-need of mechanical ventilation & \\
(n=5) (No.=\%): & \\
$\quad$ - 1ry lung disease & $2(40.0 \%)$ \\
$\quad$ - Instability of hemodynamics & $2(40.0 \%)$ \\
$\quad$ - Disturbed conscious level & $1(20.0 \%)$ \\
Type of mechanical ventilation (n=5) & \\
(No. $=\%):$ & \\
$\quad$ - Invasive & $3(60 \%)$ \\
$\quad$ - Non invasive & $2(40 \%)$ \\
Nutritional Intervention $($ No. $=\%):$ & \\
$\quad$ - No & $42(80.8 \%)$ \\
$\quad$ - Yes & $10(19.2 \%)$ \\
Sepsis (No.=\%): & \\
$\quad$ - No & $43(82.7 \%)$ \\
- Yes & $9(17.3 \%)$ \\
\hline
\end{tabular}

Table (5): Count.

\begin{tabular}{ll}
\hline Post-operative & Total $(\mathrm{n}=52)$ \\
\hline Timing of sepsis $($ No. $=\%):$ & $3(5.8 \%)$ \\
$\quad$ - Day zero & $2(3.8 \%)$ \\
$\quad$ - Day one & $1(1.9 \%)$ \\
$\quad$ - Day two & $2(3.8 \%)$ \\
$\quad$ - Day three & $1(1.9 \%)$ \\
$\quad$ - Day five & \\
Site of infection $($ No. $=\%):$ & $1(1.9 \%)$ \\
$\quad$ - Blood & $2(3.8 \%)$ \\
- Drain & $6(11.5 \%)$ \\
$\quad$ - Sputum & zero \\
$\quad$ - Others (urine, nasal) & \\
Renal Impairment $($ No. $=\%):$ & $34(65.4 \%)$ \\
$\quad$ - No & $18(34.6 \%)$ \\
- Yes & \\
Neurological complications $($ No. $=\%):$ & $43(82.7 \%)$ \\
$\quad$ - No & $9(17.3 \%)$ \\
- Yes & $6.40 \pm 2.55$ \\
ICU stay (days) (mean \pm SD) & $20.88 \pm 6.70$ \\
Hospital stay (days) (mean \pm SD) & \\
28 days mortality $($ No. $=\%):$ & $49(94.2 \%)$ \\
- No & $3(5.8 \%)$ \\
- Yes & \\
\hline
\end{tabular}

Table (6): Correlation between subjective global assessment and postoperative clinical course.

\begin{tabular}{|c|c|c|c|c|c|c|}
\hline \multirow[b]{2}{*}{ Postoperative } & \multicolumn{4}{|c|}{ Subjective global assessment } & \multirow[b]{2}{*}{$\mathrm{F} / \mathrm{x}^{2} \#$} & \multirow[b]{2}{*}{$p$-value } \\
\hline & $\begin{array}{l}\text { Well } \\
(\mathrm{n}=17)\end{array}$ & $\begin{array}{c}\text { Mild } \\
(\mathrm{n}=12)\end{array}$ & $\begin{array}{c}\text { Moderate } \\
\quad(n=17)\end{array}$ & $\begin{array}{l}\text { Severe } \\
(n=6)\end{array}$ & & \\
\hline SOFA (admission) & $8.65 \pm 3.97$ & $9.75 \pm 2.96$ & $10.82 \pm 3.34$ & $7.17 \pm 3.25$ & 2.082 & 0.115 \\
\hline SOFA (discharge) & $2.82 \pm 1.67$ & $4.08 \pm 1.44$ & $4.53 \pm 3.56$ & $5.17 \pm 6.11$ & 1.275 & 0.294 \\
\hline Time of extubation (hrs.) & $14.88 \pm 13.22$ & $11.67 \pm 2.02$ & $12.21 \pm 1.19$ & $12.17 \pm 0.75$ & 0.538 & 0.659 \\
\hline \multicolumn{7}{|l|}{ Re-need of $M . V$ : } \\
\hline No & $16(94.1 \%)$ & $10(83.3 \%)$ & $16(94.1 \%)$ & $5(83.3 \%)$ & $1.575 \#$ & 0.665 \\
\hline Yes & $1(5.9 \%)$ & $2(16.7 \%)$ & $1(5.9 \%)$ & $1(16.7 \%)$ & & \\
\hline \multicolumn{7}{|l|}{ Nutritional Intervention: } \\
\hline No & $16(94.1 \%)$ & $12(100.0 \%)$ & $11(64.7 \%)$ & $3(50.0 \%)$ & 11.289\# & $0.010^{*}$ \\
\hline Yes & $1(5.9 \%)$ & $0(0.0 \%)$ & $6(35.3 \%)^{\mathbf{a b}}$ & $3(50.0 \%)^{\mathbf{a b c}}$ & & \\
\hline \multicolumn{7}{|l|}{ Sepsis (Infection): } \\
\hline No & $16(94.1 \%)$ & $10(83.3 \%)$ & $12(70.6 \%)$ & $5(83.3 \%)$ & 3.296\# & 0.348 \\
\hline Yes & $1(5.9 \%)$ & $2(16.7 \%)$ & $5(29.4 \%)$ & $1(16.7 \%)$ & & \\
\hline \multicolumn{7}{|l|}{ Renal Impairment: } \\
\hline No & $14(82.4 \%)$ & $7(58.3 \%)$ & $10(58.8 \%)$ & $3(50.0 \%)$ & 3.377\# & 0.337 \\
\hline Yes & $3(17.6 \%)$ & $5(41.7 \%)$ & $7(41.2 \%)$ & $3(50.0 \%)$ & & \\
\hline \multicolumn{7}{|l|}{ Neurological comp.: } \\
\hline No & $15(88.2 \%)$ & $10(83.3 \%)$ & $13(76.5 \%)$ & $5(83.3 \%)$ & 0.830 & 0.842 \\
\hline Yes & $2(11.8 \%)$ & $2(16.7 \%)$ & $4(23.5 \%)$ & $1(16.7 \%)$ & & \\
\hline ICU stay (days) & $5.71 \pm 1.96$ & $5.83 \pm 1.11$ & $7.00 \pm 2.32$ & $7.83 \pm 5.27$ & 1.626 & 0.196 \\
\hline Hospital stay (days) & $19.82 \pm 4.32$ & $20.25 \pm 7.88$ & $22.47 \pm 8.44$ & $20.67 \pm 4.46$ & 0.483 & 0.696 \\
\hline \multicolumn{7}{|l|}{28 days mortality: } \\
\hline No & $16(94.1 \%)$ & $12(100.0 \%)$ & $16(94.1 \%)$ & $5(83.3 \%)$ & 2.046\# & 0.563 \\
\hline Yes & $1(5.9 \%)$ & $0(0.0 \%)$ & $1(5.9 \%)$ & $1(16.7 \%)$ & & \\
\hline
\end{tabular}

F-One Way ANOVA.

$\# \mathrm{x}^{2}$ : Chi-square test

$p$-value $>0.05 \mathrm{NS}$

${ }^{*} p$-value $<0.05 \mathrm{~S}$
Post HOC test:

a: Significant difference with "well" group.

b: Significant difference with "mild" group

c: Significant difference with "moderate" group. 
Table (7): Routes of nutritional intervention post liver transplant.

\begin{tabular}{ll}
\hline Routes of intervention & No. $(\%)$ \\
\hline None & $42(80.8 \%)$ \\
Parenteral & $7(13.5 \%)$ \\
Enteral & $2(3.8 \%)$ \\
Both (Parenteral and enteral) & $1(1.9 \%)$ \\
\hline
\end{tabular}

Table (8): Correlation between subjective global assessment and the routes of nutritional intervention.

\begin{tabular}{|c|c|c|c|c|c|c|}
\hline \multirow[b]{2}{*}{ Enteral or parenteral } & \multicolumn{4}{|c|}{ Subjective global assessment } & \multirow[b]{2}{*}{$x^{2}$} & \multirow[b]{2}{*}{$p$-value } \\
\hline & $\begin{array}{c}\text { Well } \\
(n=17)\end{array}$ & $\begin{array}{c}\text { Mild } \\
(\mathrm{n}=12)\end{array}$ & $\begin{array}{c}\text { Moderate } \\
\quad(n=17)\end{array}$ & $\begin{array}{l}\text { Severe } \\
(n=6)\end{array}$ & & \\
\hline Enteral & $0(0.0 \%)$ & $0(0.0 \%)$ & $2(11.8 \%)$ & $0(0.0 \%)$ & 4.282 & 0.236 \\
\hline Parenteral & $1(5.9 \%)$ & $0(0.0 \%)$ & $3(17.6 \%)$ & $3(50.0 \%)$ abc & 9.837 & $0.019 *$ \\
\hline Parenteral, enteral (both) & $0(0.0 \%)$ & $0(0.0 \%)$ & $1(5.9 \%)$ & $0(0.0 \%)$ & 2.099 & 0.552 \\
\hline No & $16(94.1 \%)$ & $12(100.0 \%)$ & $11(64.7 \%)^{\mathbf{a b}}$ & $3(50.0 \%)^{\mathbf{a b}}$ & 11.289 & $0.012 *$ \\
\hline $\begin{array}{l}\mathrm{x}^{2}: \text { Chi-square test. } \\
* p \text {-value <0.05 S. }\end{array}$ & $\begin{array}{l}\text { Post HOC test: } \\
\text { a: Significant } \\
\text { b: Significant } \\
\text { c: Significant }\end{array}$ & $\begin{array}{l}\text { nce with "wel } \\
\text { ence with "mil } \\
\text { nce with "mo }\end{array}$ & $\begin{array}{l}\text { up. } \\
\text { up . } \\
\text { group. }\end{array}$ & & & \\
\hline
\end{tabular}

Table (9): Correlation between subjective global assessment and liver functions.

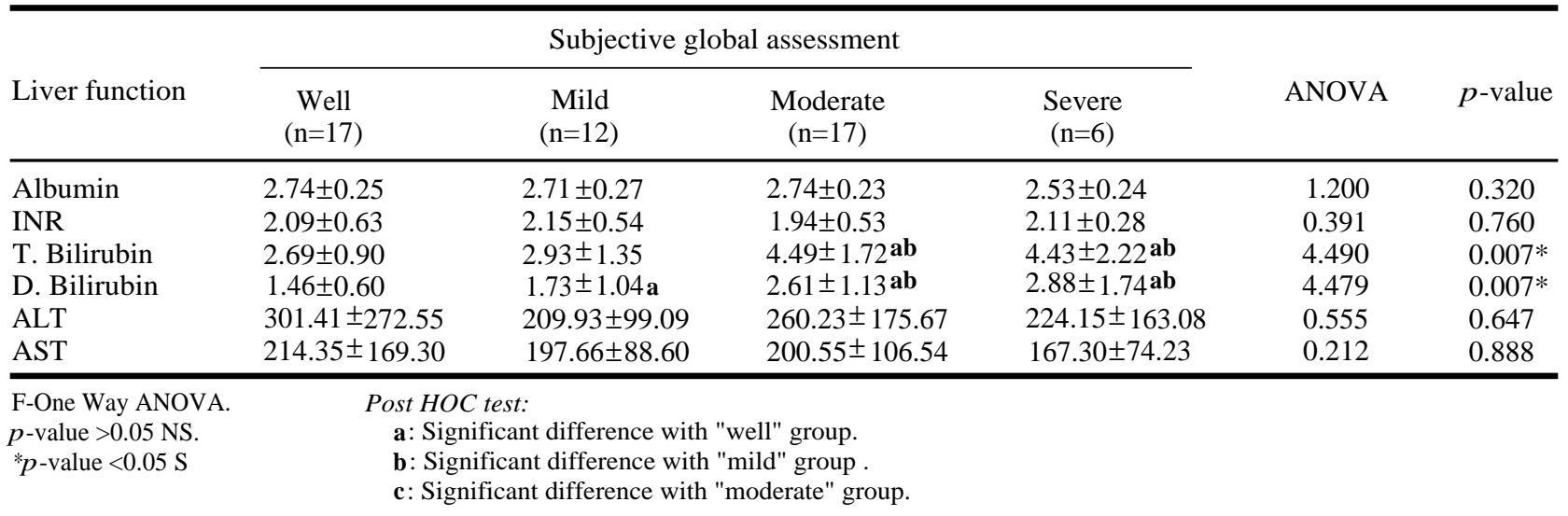

\section{Discussion}

Numerous studies have demonstrated that preoperative malnutrition is associated with high risk of surgical morbidities and mortalities in general surgical patients. Malnourished patients tend to have highest rates of infectious complications, longer intensive care unit (ICU) and hospital stays and mortality [4]

Malnutrition is associated with increased morbidity and mortality rates in patients with chronic liver disease. There is a correlation found between poor nutritional status and decreased survival rate in this group of patients [4].

In the present study the aim was to determine the impact of nutritional status pre-liver transplantation on postoperative course and outcome.
The most four relevant studies dealing with the relation between nutritional status and liver transplantation were (1) Pikul et al. [4] a retrospective single center study which was performed on 68 adult patients who had sequentially undergone liver transplant, (2) Stephenson et al. [5] a retrospective single center study which was performed on 99 adult patients who had sequentially undergone liver transplantation, (3) Merli et al. [6] a prospective single center study which was performed on 38 consecutive adult patients who undergone liver transplantation, and (4) Yosry et al. [7] prospective multi-center study performed on 30 adult male patients with ESLD who had undergone liver transplantation.

In the present study, regarding patients' demographic variables; age ranged $(47.77 \pm 9.77)$ years 
which had no statistical significance in correlation with subjective global assessment ( $p$-value 0.962). As the average in all groups were nearly equal.

In contrast to the present study results, Pikul et al. [4] showed that well-nourished and mildly mal-nourished patients were significantly younger than severely mal-nourished patients ( $p$-value $<0.05)$.

Stephenson et al. [5] and Yosry et al. [7] showed that (mean \pm SD) age were $(47 \pm 2.3)$ and $(50.3 \pm 4.85)$ years respectively and were also statistically nonsignificant in correlation with subjective global assessment. Merli et al. [6] found that average of age was $(50 \pm 11)$ years in well-nourished patients while the average of age in mal-nourished patients was $(54 \pm 9)$ years.

Regarding the gender; present study did not show any statistical significance in correlation with subjective global assessment ( $p$-value 0.108 ).

In contrast to the present study, Hasse et al. [8] showed statistically significant correlation between the gender and the degree of mal-nutrition ( $p$-value 0.001 ), as nutritional status of females was better than males. In Hasse et al. [8] study females represented $(47.6 \%)$ in comparison with the present study which represented only (17.3\%) that's which could explain the difference between the present results and other studies.

Merli et al. [6] showed also that there was no statistical significance between the gender and the degree of mal-nutrition ( $p$-value 0.86 ).

Regarding BMI, the present study showed a statistically significant relation between weight and BMI in severely mal-nourished patients and SGA ( $p$-value $<0.003$ and $<0.001$ ) respectively.

Merli et al. [6] showed that BMI in wellnourished and mal-nourished patients' average $(26.8 \pm 2.8)$ and $(24.4 \pm 3.5) \mathrm{kg} / \mathrm{m}^{2}$ respectively with a statistical significant correlation with subjective global assessment ( $p$-value $<0.02$ ).

In contrast to the present study, Yosry et al. [7] study showed that BMI in moderate and severe mal-nourished patients average $(28.4 \pm 3.78) \mathrm{kg} / \mathrm{m}^{2}$ and did not show any statistical significant correlation with subjective global assessment.

In the present study, the overall incidence of malnutrition was $67.3 \%$; mild mal-nourished patients represent $23.1 \%$, while moderate malnourished represent $32.7 \%$ and severe malnourished represent $11.5 \%$.
Pikul et al. [4] showed that overall incidence of malnutrition in study group was $79 \%$; mild malnourished patients represented 19\%, moderate malnourished patients represented $34 \%$ while severe mal-nourished patients represented $26 \%$ of the study population.

Stephenson et al. [5] found that mild malnourished patients represented $35.4 \%$, moderate and severe mal-nourished patients' both represented $32.3 \%$ of the study population.

While in the study done by Merli et al. [6] patients divided according to subjective global assessment into well-nourished (SGA-A) who represented $(47.4 \%)$ and mal-nourished (SGA-B and C) represented $(52.6 \%)$ of the total study population.

In the study performed by Yosry et al. [7], moderate mal-nourished group represented (53.3\%) while severe mal-nourished group represented (46.7\%) of the total mal-nourished patients.

In the present study, the etiology of liver transplant was mainly decompensated CLD which represented $(46.2 \%)$ of enrolled patients. Hepatocellular carcinoma represented $(32.7 \%)$ and autoimmune with HCC represented (11.5\%). Patients who were well-nourished had the least cause of decompensated CLD in comparison with the other three groups and this had statistically significant $p$-value (0.004 and 0.005) respectively.

Pikul et al. [4] showed that the etiology of liver transplantation was mainly due to chronic active hepatitis $(n=20)$, primary biliary cirrhosis $(n=17)$ and alcoholic liver disease $(n=13)$ and they did not show any statistically significant correlation with subjective global assessment.

Stephenson et al. [5] study revealed that etiology of liver transplantation was hepatitis $C(n=40)$, cryptogenic cirrhosis $(n=14), \operatorname{PSC}(n=11)$ and autoimmune hepatitis $(n=4)$ and they did not show any statistically significant with subjective global assessment.

In the present study, pre-transplant liver status (Child-Pugh score) ranged (9.40 \pm 1.99$)$; Child C mainly represented $63.5 \%$ (33 patients), as the mal-nutrition grade became worsen, the ChildPugh score became higher. Well-nourished patient group showed the least Child C status (29.4\%) in comparison to the mal-nourished patient groups $(66.7 \%, 88.2 \%$ and $83.3 \%$, respectively) and the overall Child-Pugh score was significant statistically lower in well-nourished patient in comparison to the mal-nourished group ( $p$-value $<0.001$ ). 
Merli et al. [6] showed that pre-transplant liver status (Child-Pugh score average (7.8 \pm 2$)$ in wellnourished group while average was $(9.7 \pm 1.6)$ in mal-nourished group and this correlation had statistically significant value ( $p$-value 0.004$)$ with SGA.

In Yosry et al. [7] study the pre-transplant liver status (Child-Pugh score) was child A, B represented together $(43.3 \%)$ of the study population and child C represented $(56.7 \%)$.

In the present study, pre-operative creatinine clearance was higher in well-nourished group than in mal-nourished groups however this difference was not statistically significant value ( $p$-value 0.097).

Regarding the post-operative course of the present study population; sepsis occurred in 9 patients representing $(17.3 \%)$ of the total study groups. Sepsis developed in one patient of the well-nourished group (5.9\%) while the remaining 8 patients occurred in mal-nourished groups $(62.8 \%)$.

Merli et al. [6] showed that both the total number of infective episodes and the number of infections per patient were highly significant in mal-nourished patients when compared with well-nourished patients ( $p$-value $<0.000001$ and $<0.0001$ ) respectively.

Yosry et al. [7] showed increased number of infection episodes in severe mal-nourished patients and it was statistically significant ( $p$-value 0.002 ).

In the present study, there was no statistically significant correlation between subjective global assessment and INR, ALT and AST. Nevertheless, there was statistically significant correlation between SGA and total bilirubin ( $p$-value 0.007). Direct bilirubin was highest in both moderately and severely mal-nourished patients.

In contrast to the present study, Yosry et al. [7] showed statistically significant correlation between subjective global assessment and INR ( $p$-value 0.005 ), and there was also statistically significant differences with the other liver functions including; T. bilirubin, ALT and AST ( $p$-value 0.9).

Nutritional interventions were indicated in one patient in well-nourished group (5.9\%) while $(35.3 \%$ and $50 \%)$ of the moderate and severely mal-nourished group patients were in need for post-operative nutritional intervention ( $p$-value $<0.001)$. The parenteral route was needed for nutritional intervention in $(50 \%)$ of severe mal- nourished patients in comparison to $(5.9 \%)$ of wellnourished patients. It was difficult to compare the result of the present study with other studies as there were no studies discussing this point.

The time of extubation was statistically nonsignificant between the study groups; it was higher in well-nourished patients, however the re-need for mechanical ventilation was much higher in mal-nourished patients $(11,4 \%)$ in comparison to the well-nourished patient group (5.9\%).

Regarding the post-operative renal function, $17.6 \%$ of well-nourished group patients showed some degree of renal impairment in comparison to a much higher incidence in mild, moderate and severe mal-nourished groups $(41.7 \%, 41.2 \%$ and $50 \%$ ) respectively.

In agreement with our study, Stephenson et al. [5] found that severely mal-nourished group had statistically significance higher post-operative serum creatinine level in comparison to the mildly and moderately mal-nourished patients.

The result of the present study revealed a higher incidence of neurological complications in moderately mal-nourished group patients $(23.5 \%)$ in comparison to well-nourished are (11.8\%).

All these complications were reflected on the value of SOFA on ICU discharge. The mean SOFA score in well-nourished group was $2.82 \pm 1.67$ in comparison to $5.17 \pm 6.11$ in severely mal-nourished patients.

AS a result of all these complications, the ICU stay, hospital stay and the 28 day mortality was shorter in well-nourished patients in comparison to the mal-nourished patients. The average time of ICU stay in well-nourished patients was $5.71 \pm$ 1.96 in comparison to $7.83 \pm 5.27$ in severe malnourished patients. The 28 day mortality incidence was $5.9 \%$ in well-nourished patients in comparison to $16.7 \%$ in severely mal-nourished patients.

Pikul et al. [4] showed that there was significant increase in the length of ICU stay, hospital stay in the moderate and severe mal-nourished patients when compared with well-nourished and mild malnourished patients ( $p$-value $<0.05$ ). There was an association between the degree of malnutrition and mortality rate ( $p$-value 0.03 ), patients with moderate to severe malnutrition had higher mortality rates.

In agreement with the present study, Selberg et al. [2] found that patients with a better nutritional status at time of transplantation had improved survival rates after LT. 
Hasse et al. [8] showed that moderate and severe mal-nourished groups had statistically significant longer ICU stay ( $p$-value 0.001).

Stephenson et al. [5] showed that severe malnourished patients had statistically significant longer hospital stay compared with mild and moderate mal-nourished patients.

The study of Merli et al. [6] revealed statistically significant correlation between the degree of malnutrition and ICU stay ( $p$-value 0.0007), hospital stay ( $p$-value 0.0001 ), while mortality did not show any statistically significant correlation with the degree of mal-nutrition ( $p$-value 0.1 ).

Yosry et al. [7] showed that severe malnourished patients had longer ICU stay ( $p$-value 0.02 ); furthermore the poor nutritional status had been associated with increased morbidity, mortality, longer dependency on mechanical ventilation, and longer hospital stay.

\section{Conclusion:}

The nutritional status pre-liver transplant is an important factor which can affect the outcome of the liver transplant patients. The mal-nourished patients showed a higher incidence of postoperative sepsis, a higher post-operative bilirubin levels, a more need for post-operative nutritional intervention, a higher incidence of need of reintubation for mechanical ventilation, a higher incidence of post-operative renal impairment and neurological complications. As a result of all these complications, the ICU stay, hospital stay, 28 day mortality were less in well-nourished patients in comparison to the mal-nourished one. So, pre- operative assessment and optimizing the nutritional status is an essential step before proceeding for surgery.

\section{References}

1- FRANCESCO P.R., ALBERTO F. and ALBERTO Z.: Recent advances in understanding and managing liver transplantation. Published online 2016 21. Version 1. F1000 Res., 2016.

2- SELBERG O., BÖTTCHER J., TUSCH G., et al.: Identification of high and low risk patients before liver transplantation: A prospective cohort study of nutritional and metabolic parameters in 150 patients. Hepatology, 25: 652-7, 1997.

3- HENKEL A.S. and BUCHMAN A.L.: Nutritional support in patients with chronic liver disease. Nat. Clin. Pract. Gastroenterol. Hepatol., 3 (4): 202-9, 2006.

4- PIKUL J., SHARPE M.D., LOWNDES R., et al.: Degree of preoperative malnutrition is predictive of postoperative morbidity and mortality in liver transplant recipients. Transplantation, 57 (3): 469-471, 1994.

5- STEPHENSON G.R., EUGENE W.M., HABIB E., et al.: Preoperative subjective global assessment is predictive of outcome after liver transplantation. Transplantation, 72 (4): 666-670, 2001

6- MERLI M., MICHAELA G., FEDERICA G., et al.: Nutritional status: It's influence on the outcome of patients undergoing liver transplantation. Liver International, (1478-3223): 208-214, 2009.

7- YOSRY A., DALIA O., MOHAMAD S., et al.: Impact of nutritional status of Egyptian patients with end-stage liver disease on their outcomes after living donor liver transplantation. Journal of Digestive Diseases, 15: 321 326, 2014.

8- HASSE J.M., GONWA T.A., JENNINGS L.W., et al.: Malnutrition affects liver transplant outcomes. The American Society of Transplant Physicians, 65 (12): 53, 1998.

\section{تقييم الحالة التغلدوية كمؤشر تنبؤى فى مرضى زراعة الكبد}

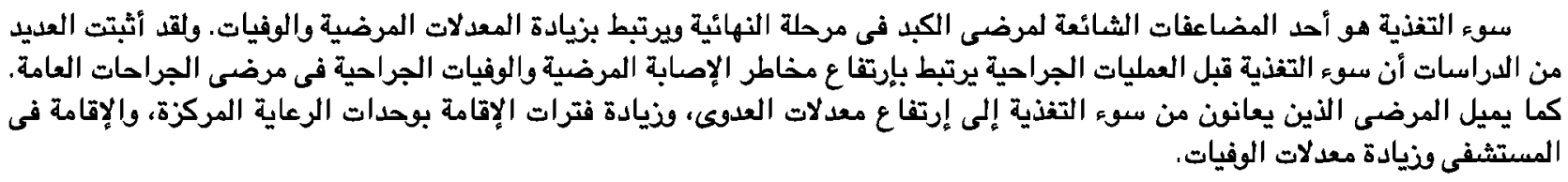

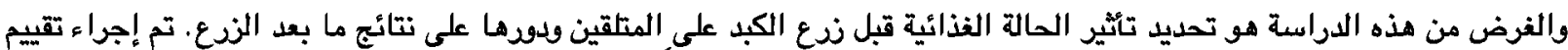

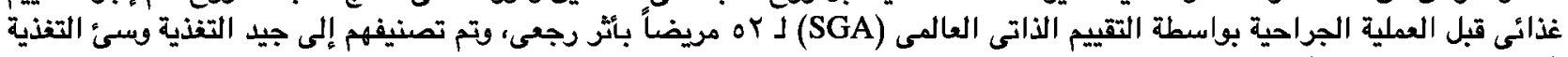

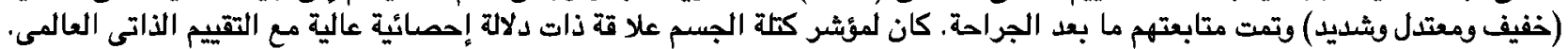

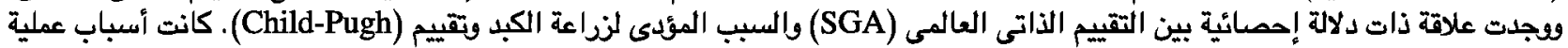

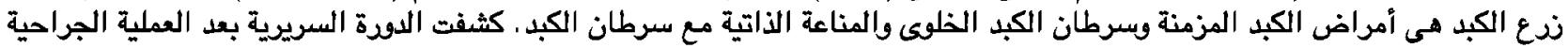

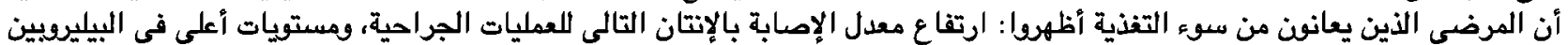

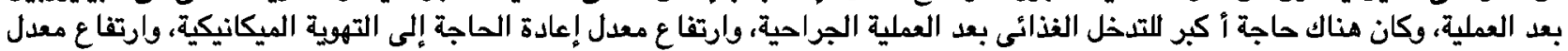

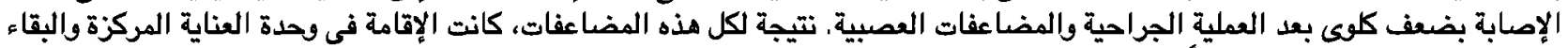

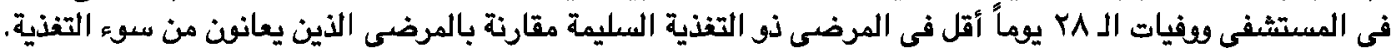

